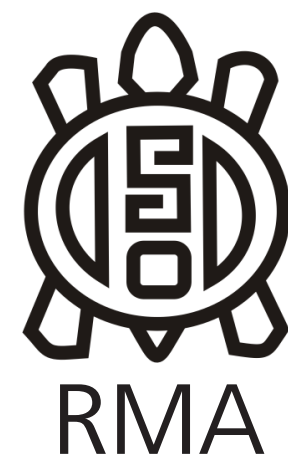

Antropología Social

\title{
La animalidad en cuestión: derechos, ontologías, moralidades y políticas
}

\author{
Animality in question: rights, ontologies, moralities and politics
}

María Carman

CONICET - Universidad de Buenos Aires. Instituto Gino Germani. Buenos Aires, Argentina. E-mail: mariacarman1971@gmail.com

\begin{abstract}
Resumen
En este artículo quiero analizar críticamente los postulados de la corriente de pensamiento que ha servido de sustento a la militancia a favor del derecho animal: el antiespecismo. Luego de un breve repaso por el surgimiento histórico de esta corriente, he de comentar los principales rasgos del giro animal del pensamiento.

Desde mi punto de vista, no hay en estas formulaciones ni gran novedad ni ruptura sustantiva con el statu quo. En primer lugar, el pensamiento occidental reactualiza bajo su propio horizonte de sentido lo que muchas sociedades indígenas no han dejado de experimentar en su vida ordinaria desde muchísimo tiempo atrás: la atribución de humanidad a los animales y la vivencia de una interconexión entre los seres. Por otra parte, el giro animal del pensamiento no propone un horizonte político claro, ni tampoco tematiza qué ha de suceder cuando algún derecho animal entre en conflicto con las posibilidades de supervivencia de un grupo humano específico.
\end{abstract}

Palabras clave: antiespecismo; giro animal; biocentrismo; sensocentrismo; antropocentrismo.

\begin{abstract}
This article critically examines anti-speciesism, a school of thought that serves to support animal rights advocacy. After briefly reviewing the history of this approach I will comment on the main features of the animal turn.

In my view, there is nothing really new or substantially anti- status quo/counter-hegemonic in these claims. First of all, Western thought is revising -within its own horizon of understanding- what many indigenous societies have experienced in their everyday lives for a long time: attributing humanity to animals and experiencing an interconnection between beings. In addition, the animal turn of thought does not offer a clear political horizon, nor does it consider what would happen if an animal right were to conflict with the survival of a specific human group.
\end{abstract}

Keywords: anti-speciesism; animal turn; biocentrism; sentiocentrism; anthropocentrism.

¿Qué cambios han operado en las sociedades occidentales relacionados con nuestros vínculos con la naturaleza? ¿Bajo qué operaciones se impugna, fragmenta o contesta la ontología moderna dominante? ¿Debe la justicia circunscribirse al dominio humano?

En este artículo quiero analizar críticamente los postulados de la corriente de pensamiento que ha servido de sustento a la militancia a favor del derecho animal: el antiespecismo. Luego de un breve repaso por el surgimiento histórico de esta corriente, he de comentar ciertos rasgos del giro animal del pensamiento. Como introducción a esta problemática, el artículo repasa la ubicuidad de las causas ambientales o de la defensa de la naturaleza en las sociedades occidentales.

A continuación se presentan algunos aportes teóricos relevantes de la disciplina de la Antropología de la
Naturaleza en relación a la distinción animal-humano, así como otras miradas contemporáneas que también impugnan la primacía humana en el podio de lo viviente. He de trazar además una distinción entre el biocentrismo, el antropocentrismo crítico y el antropocentrismo convencional, que será retomado en las conclusiones del trabajo.

\section{La ubicua retórica ambiental}

La defensa de la naturaleza suele revestirse con el camuflaje de aquello que resulta desinteresado, evidente y universal. La antropología, no obstante, ha demostrado hasta el cansancio que toda percepción de lo natural se apoya en juicios de valor, que no son sino aspectos de una cultura. Toda noción de naturaleza se construye por oposición a otra cosa. La naturaleza puede ser, incluso, 
una categoría ausente en una cultura'

Resulta imprescindible comprender la importancia o vacuidad de los conceptos de naturaleza y cultura en el contexto de una determinada ontología. En el mismo sentido, las preguntas por la naturaleza humana, la naturaleza animal de la humanidad o los derechos de los animales tampoco son universales².

Hasta la Edad Media, las personas no se consideraban ajenas al resto de su entorno: basta evocar el terror que inspiraban las fuerzas naturales o los juicios perpetrados contra cerdos y gallos ${ }^{3}$. Con el advenimiento de la modernidad y la consiguiente fractura entre cultura y naturaleza, esta última se convierte en un recurso que ha de ser conocido, conquistado y explotado. En efecto, para la cosmovisión naturalista, la naturaleza existe como un dominio autónomo y los humanos formamos parte de colectividades diferenciadas que excluyen al conjunto de los no humanos. Si bien existe una continuidad material entre animales y humanos, al mismo tiempo se proclama la discontinuidad de sus interioridades ${ }^{4}$.

Pese a la disyunción entre naturaleza y cultura inherente a la cosmovisión occidental, algunas sensibilidades ecologistas proclaman una compenetración con la Madre Tierra que las aproximaría a una perspectiva ontológica propia de los pueblos indígenas. Parte del ambientalismo contemporáneo asume como propia la postura biocéntrica de pertenecer a un solo mundo habitado por una multiplicidad de seres, entre los cuales se incluyen los humanos; un mundo que estaría asolado por una sola y gigantesca crisis ambiental. No obstante, los contrapuntos entre las cosmovisiones ecologistas -que surgen en el seno de nuestra sociedad moderna- y las ontologías indígenas son múltiples. Una diferencia relevante entre ambas refiere a los planteos deterministas inversos implicados. En tanto algunas

\footnotetext{
Como señala Descola (en Chaplier, 2005: 34), la parte de la materialidad que no ha sido directamente engendrada por el hombre y que llamamos naturaleza puede ser representada en ciertas sociedades como un elemento distintivo de su cultura. Véase además Milton (1997).

2 Véase Tapper (1994: 49).

3 Los animales "testificaban" en las cortes previctorianas con su presencia, e incluso eran condenados por sus crímenes (véase Ritvo en Passariello, 1999: 16). También hay antecedentes de grupos aborígenes que "enjuician" animales. Transcribo un bello pasaje de Frazer (2011: 409): "Varias tribus de Madagascar se creen descendientes de cocodrilos y en consecuencia consideran al reptil escamoso, para todos los efectos, como un hombre y un hermano. Si alguno de los cocodrilos lo olvidase hasta el punto de devorar a uno de sus parientes humanos, el jefe de la tribu (...) se encamina a la cabeza de la gente al borde del agua y conmina a la familia del culpable para que lo entreguen al brazo de la justicia. (...) [D]espués que se le ha hecho comprender claramente su crimen por un interrogatorio estricto, es sentenciado a muerte y ejecutado".

${ }^{4}$ En las grandes religiones monoteístas, la discontinuidad de las interioridades entre humanos y animales adquiere un sesgo metafísico, que justifica el dominio de los primeros sobre los segundos (Nussbaum, 2007: 383). La defensa de esa discontinuidad puede rastrearse en Sócrates, Platón, los sofistas, los estoicos, y los primeros padres de la Iglesia (véase Simondon, 2004).
}

comunidades indígenas conciben la naturaleza -si es que tal noción existe como tal- como una fuerza que los maneja, las sociedades industriales afirman, por el contrario, su dominio para gestionar esa naturaleza (Pretty et al. 2008: 3).

¿Qué significa apoyar una buena causa ambiental? ¿De qué modo el altruismo frente a los dramas ecológicos del mundo colma de sentido a sus practicantes? Un número significativo de reivindicaciones ecologistas se estructuran en torno de una microética individual característica de la modernidad ${ }^{5}$ : la creencia de que una catástrofe ambiental puede ser remediada a partir de los cambios en los comportamientos de cada ciudadano es un ejemplo de ello. La suma de miles de buenas voluntades individuales serían capaces de salvar a las ballenas, el agua o el mono tití -uno de los modos de salvar, metonímicamente, al Mundo- de su destino apocalíptico ${ }^{6}$.

Como podemos comprobar a diario, el ambientalismo atraviesa todo el arco político ${ }^{7}$. Así como algunos movimientos ecologistas incorporan explícitamente proclamas anticapitalistas, no es menos cierto que el medio ambiente constituye una de las ideologías dominantes de aquello que Boltanski y Chiapello (2002: 39-47 y 556-567) denominan el nuevo espíritu del capitalismo.

Si bien el capitalismo constituye "...la principal forma histórica organizadora de las prácticas colectivas que se encuentra absolutamente alejada de la esfera moral" (ibid.: 61), esto no impide que utilice en forma eficaz el discurso del medio ambiente, que se distingue por su marcada impronta moral. Y es que,

“...para mantener su poder de movilización, el capitalismo debe incorporar recursos que no se encuentran en su interior, acercarse a las creencias que disfrutan, en una época determinada, de un importante poder de persuasión y tomar en consideración las ideologías más importantes incluidas aquellas que le son hostiles- que se encuentran inscriptas en el contexto cultural en el cual se desarrolla. [...] El capitalismo, enfrentado a una exigencia de justificación, moviliza algo que "ya está ahí", algo cuya legitimidad se encuentra ya garantizada y a lo cual dará un nuevo sentido

\footnotetext{
5 Un desarrollo interesante de cómo esta microética a la cual nos confina la modernidad no logra ser reemplazada por una macroética puede encontrarse en Santos (1998: 106).

6 Einarsson (1993: 73) acota mordazmente que la degradación ambiental del planeta es percibida hoy -al igual que alguna vez lo fue la guerra nuclear- como la peor amenaza para la humanidad; o al menos así parece suceder en aquellos países donde la gente no debe preocuparse por la comida de todos los días.

7 Milton (2002: 29) ha consignado interesantes ejemplos de argumentos posicionados en veredas opuestas de los debates ambientales que se aúnan en una "campaña verde" o conviven bajo un mismo marco institucional.
} 
asociándolo a la exigencia de acumulación de capital". (Boltanski y Chiapello, 2002: 61).

Todos somos necesariamente verdes, aun quienes contaminan. ¿Qué infamia, qué irreversible descrédito recaería sobre el actor social que no se ajustara a esa retórica? Como apunta Beck (2009: 72), la moderna aura ecológica carece en apariencia de adversario. En este panorama tan incierto y contradictorio, ¿cuál puede ser el aporte de la Antropología para pensar las problemáticas medioambientales y, más específicamente, las fronteras entre lo animal y lo humano?

Existe cierto consenso entre los autores más destacados de la Antropología de la Naturaleza respecto de las distinciones básicas entre el hombre y el animal o bien -en términos ya no tan antropocéntricos- sobre qué es aquello que vuelve a los humanos un tipo particular de animales (Descola, 2009: 18).

Ingold (1994c: 84-99) afirma que la producción de artefactos depende de una capacidad de pensamiento simbólico característica del Homo sapiens que se basa en su facultad de lenguaje. Otras de las singularidades de nuestra especie se vinculan con invenciones deliberadas y la activa adquisición de cultura -en detrimento de una pasiva absorción de la tradición- que permite una acumulación de conocimiento. Aunque existen facultades intelectuales exclusivas de los humanos, Ingold considera que la mayor parte de la conducta humana no difiere sustancialmente de la animal. Esa conducta compartida coincide con aquello que Giddens (1995) conceptualiza como una conciencia práctica.

Si bien animales y humanos actuamos como agentes intencionales, los seres humanos eventualmente nos valemos de una conciencia discursiva: tenemos la capacidad de discernir nuestros propósitos y articularlos en un discurso. No obstante $-y$ en esta apreciación coinciden Giddens e Ingold ${ }^{8}$-, los humanos no pensamos tanto antes de actuar: al igual que los animales, estamos inmersos en la acción. Para graficar esta cuestión, Ingold (1994c: 96) sostiene que el lenguaje proposicional y completamente articulado no es la norma de la comunicación humana sino "...la punta del iceberg comparada con la masa de comunicación espontánea, no verbal que compartimos con otros animales". Esta corriente de la Antropología busca distanciarse, en fin, de aquello que Descola (2009: 156) define como un dogma naturalista: la creencia en la absoluta singularidad de la humanidad.

\footnotetext{
8 Véase también Descola (1996: 86); Bourdieu (1991, capítulo III); Merleau-Ponty (1997); Ellen (1996); Escobar (2000); y Murrieta (2001). Aristóteles ya había consignado que el hombre, a diferencia del animal, cuenta con la capacidad de deliberación, vale decir: de libre elección a partir del examen de sus posibilidades de acción (Simondon, 2004: 41-52). Una crítica a las nuevas fenomenologías de la percepción y teorías antimentalistas de Ingold y otros autores puede encontrarse en Descola (2012: 278-287).
}

Si la humanidad no es una característica de los individuos en abstracto, sino una cualidad construida y limitada por su interacción con otros humanos (Turner, 2010: 59), esa cualidad también se despliega en sus actividades materiales y su relación cotidiana con un conjunto de seres no humanos y un entorno.

\section{La continuidad animal/humano}

Hacia el final de Las palabras y las cosas, Foucault (2012) sugiere que el hombre no es el problema más antiguo ni más constante que se haya planteado al saber occidental. ¿Dónde empieza y dónde acaba aquello que concebimos como humano? ¿Qué contenidos disímiles y hasta contradictorios abarca nuestra percepción de la humanidad? Si luego de 50 años de la Declaración Universal de los Derechos del Hombre aún debemos preguntarnos qué es lo humano (Bhabha, 2013: 71), el interrogante también pertenece vigente respecto de qué es lo animal.

Al igual que el humano, el animal accede al doble estatus de objeto a ser conocido, explorado y develado en sus intrincados mecanismos, aunque sin perder su estatus de sujeto sintiente. Ya no es solo el hombre quien puede ser conocido a través de la vida, el lenguaje y el trabajo, como planteaba Foucault (2012: 327): ciertos animales despiertan una intensa curiosidad en torno a su ADN, sus balbuceos y formas expresivas y los objetos que pueden manipular. Diversas investigaciones arrojan inquietantes conclusiones sobre su proximidad genética y sus habilidades emocionales. Los contornos de una supuesta condición moral en los animales se revelan más nítidos en aquellas especies que resultan más cercanas a la experiencia del hombre, ya sea por su carácter doméstico o por sus "logros" y cualidades.

Una serie de estudios científicos demuestran que los delfines usan herramientas y que los grandes simios toman decisiones sofisticadas ${ }^{9}$. La inteligencia o la piedad vuelven a estos animales semejantes al hombre, hasta el extremo de ser considerados "más humanos que los humanos" (Hallowell en Viveiros de Castro, 2010: 37). Como bien sintetiza Descola (2012: 272), el consenso naturalista en una interioridad distintiva de los humanos se ve debilitada actualmente no solo por ciertos desarrollos de la ética y el derecho, sino de las ciencias.

¿Qué humanos, qué animales, qué objetos están dotados socialmente de valor y cuáles, en cambio, son desechables? De la cantera inagotable que es el mundo animal como espejo de nosotros mismos, se extraen metáforas de contenidos opuestos. La animalidad puede ser comprendida como un dominio que incluye a los humanos, o bien como un estado opuesto a la

\footnotetext{
${ }^{9}$ Véase al respecto www.proyectogransimio.org, o bien la imputación de culturas diferenciadas a los chimpancés (Descola, 2005 y 2012: 270-278).
} 
humanidad $^{10}$. En esta segunda acepción, volverse humano equivale a superar la condición animal.

Si lo animal es lo familiar -aquello que está unido al afecto, que es próximo a nosotros y a un ideal moral-, puede transformarse en siniestro cuando se encarna en comportamientos considerados salvajes. En este sentido, el concepto de animal en el mundo occidental se construye básicamente por default; como una suma de deficiencias de aquellos atributos que nosotros tendríamos en forma única ${ }^{11}$.

¿De qué formas se acorta actualmente esa distancia que se suponía imperturbable entre el mundo humano y el animal? Dos premisas ontológicas características de los pueblos indígenas -que los animales son, o pueden ser, personas; y que participan en el mismo mundo que nosotros (Ingold, 1994a: XXIII)- comienzan a ser defendidas, con matices específicos, en distintos estrados de Occidente.

Lejos de estimarlos como objetos, un creciente número de colectivos -activistas ambientales, juristas, filósofostiende a concebir a los animales como sujetos no humanos cuya actividad esencial consiste en percibir y actuar en un medio ambiente que no es un dominio de objetos neutros, sino una suerte de prolongación de su propio cuerpo (Ingold, 2000: 176).

La tesis de la proximidad animal/humano -o al menos de una continuidad entre el psiquismo humano y el psiquismo animal- se encuentra en una tradición del pensamiento occidental que nos remonta a autores como Pitágoras, Anaxágoras, Aristóteles, Giordano Bruno, San Francisco de Asís, Hobbes y Montaigne ${ }^{12}$. Así como el dualismo cartesiano redujo el animal a un pseudoviviente que representaba todo lo que el hombre no era, un curioso retorno de las cosas recoge las primeras tesis de continuidad animal/humano de los filósofos de la Antigüedad: aquello que es verdadero en la realidad animal -respecto de la vida instintiva o el desarrollo del comportamiento- es verdadero también

\footnotetext{
${ }^{10}$ Véase Ingold (1994b: 4-5). El autor propone conocer los animales de un modo similar al que Lévi-Strauss utilizó para conocer los mitos: "Así como una comprensión profunda del mito [...] puede ser obtenida a partir de una lectura simultánea de sus muchas versiones, quizás podamos llegar más cerca de una comprensión del significado de lo animal tratando cada taxonomía como una de un set, cada una proveyendo una respuesta parcial al problema cuya [...] solución requiere una lectura del set entero como una totalidad estructurada" (ibid.: 2-3, mi traducción). En términos de Latour (2004: 319), lo que nos vuelve humanos es, precisamente, el vínculo con los no humanos. 11 Véase al respecto Ingold (1994b: 2-3) y Tapper (1994: 52). En latín, nos recuerda Quignard (2010: 60), la infancia quiere decir lo no hablado: in-fantia. En las visiones que heredamos de las civilizaciones europeas, lo animal es la infancia del hombre: una especie de hombre sin lenguaje. El humano, sugiere Quignard, está alcanzado por una animalidad de la que se quiere desprender. En la Antropología contemporánea, autores como Ingold (1994) desarticulan esta difundida creencia.

12 Véase Simondon (2004); Rosset (1965); Agamben (2002: 16, 125 129); y Descola (2012: 110-117 y 265-270).
}

en la realidad humana (Simondon, 2004: 58-63).

La revisión de la primacía humana en el podio de lo viviente abre nuevas perspectivas para interpretar de qué modo humanos y animales pueden haberse desarrollado en su interrelación: la perspectiva de la ecología de la mente de Bateson, la hipótesis Gaia de Lovelock y la emergencia de los movimientos verdes y de derechos de los animales dan cuenta de un descentramiento de lo humano en pos de una cooperación, codomesticación o coevolución (Passariello, 1999: 17).

Por su parte, el rescate de la dignidad animal entre los activistas exhibe una nostalgia por una proximidad que no necesariamente existió: se lucha, en ocasiones, por los derechos de animales con los que jamás se ha tenido una experiencia directa. Los grupos más identificados con la defensa de animales salvajes suelen provenir de sociedades industriales con un trato acotado con animales no domésticos en su vida cotidiana. Aunque el contacto sea limitado, los animales nos llegan por múltiples vías. Tapper (1994: 51) zanja este asunto con la debida belleza: siempre hay animales alrededor, incluso cuando solo existen como imágenes en nuestra mente.

En los próximos apartados veremos de qué modo diversos colectivos esgrimen que no existe tal tajante cesura entre la interioridad del ser humano y el animal, o bien entre los humanos y la naturaleza.

\section{Derechos de los animales, derechos de la naturaleza}

En el campo del derecho europeo, la corriente animalista confiere a los animales "un lugar intermedio entre el humano y las cosas, como entes capaces de sentir y de sufrir" (Zaffaroni, 2012: 57). Estas capacidades son tuteladas en leyes especiales de los códigos civiles de Suiza, Alemania, Gran Bretaña, Francia y Austria. En las últimas décadas se fueron sancionando iniciativas tanto en Europa como en Estados Unidos- para prohibir el confinamiento en jaulas de los animales de granja. En 2008 se votó en España la concesión del estatus legal de persona con derechos a un animal; lo cual constituye, según Singer (2011: 16), "la primera aceptación oficial de las implicaciones legales y morales derivadas del reconocimiento de las similitudes entre nosotros $y$, al menos, algunos animales no humanos".

En América Latina, el llamado giro biocéntrico supone un avance jurídico distinto: no se limita a la inclusión del ambiente en los derechos de tercera generación. La Constitución de Ecuador (2008) asume a la Pachamama como sujeto de derechos, lo cual no solo implica que cualquier individuo puede ejercer acciones en su defensa, sino que esta tiene valores intrínsecos, independientes de los intereses de los humanos (Gudynas, 2015: 41). Esta carta magna impugna una concepción de la política que incluya únicamente a los seres humanos en tanto 
sujetos de derechos.

Como sustento filosófico, tanto la Constitución de Ecuador como la Constitución de Bolivia (2009) retoman las nociones indígenas del Buen Vivir, que designan la vida armoniosa entre los humanos y la naturaleza. La idea del Buen Vivir es nombrada como sumak kawsay en kichwa, mientras que en Bolivia se la invoca como Vivir Bien: suma qamaña en aymara y ñandareko en guaraní13.
"Art. 71.- La naturaleza o Pacha Mama, donde se reproduce y realiza la vida, tiene derecho a que se respete integralmente su existencia y el mantenimiento y regeneración de sus ciclos vitales, estructura, funciones y procesos evolutivos. (...)
Art. 74.- Las personas, comunidades, pueblos y nacionalidades tendrán derecho a beneficiarse del ambiente y de las riquezas naturales que les permitan el buen vivir". (Constitución de la República del Ecuador, 2008).

En su extraordinaria etnografía sobre los achuar del Amazonas, Descola (1996: 308-322) utiliza el término good life (shiir waras) para referir al ideal de una vida armoniosa vinculada con tener paz en casa y un estado de equilibrio en el uso de la naturaleza, alejado de una acumulación sin fin de artículos de consumo. Uno de los criterios fundamentales de la buena vida remite a la habilidad para asegurar la reproducción doméstica explotando solo una pequeña fracción de los recursos existentes. Para los achuar, la naturaleza es gobernada por las mismas relaciones sociales que rigen en la casa, por lo cual no es domesticada ni domesticable, sino simplemente doméstica. La praxis diaria de este pueblo, sintetizada en la noción de buena vida, confirma una correspondencia entre los modos de relacionarse con la naturaleza y los modos de relacionarse con los otros ${ }^{14}$.

En un sentido similar, la cosmovisión andina del vivir bien no está centrada en el individuo sino "...en la complejidad e inmanencia de la Madre Tierra y el cosmos, considerados como matrices vivas e integradas por fuerzas animistas" (Prada en Schavelzon, 2015: 212). Creo que el Buen Vivir puede ser concebido, parafraseando a Århem (2001: 215), como una ecocosmología que integra conocimientos prácticos y valores morales, ofreciendo lineamientos significativos para una existencia plena. La vastedad del tema merece, sin embargo, un abordaje detallado que excede los fines de este trabajo: las diferentes acepciones del Buen Vivir ${ }^{15}$; el estrecho vínculo de este concepto con

\footnotetext{
${ }^{13}$ Véase Gudynas y Acosta (2011: 103).

${ }^{14}$ Haudricourt en Descola (1996: 327).

15 Se trata de un concepto ecléctico que es usado por diversos actores para fines antagónicos. Este antagonismo resulta evidente en la caracterización que realizan Le Quang y Vercoutère (2013) sobre las principales corrientes que defienden el Buen Vivir: la culturalista, la
}

los de plurinacionalidad, autonomía y comunidad; las implicancias sociopolíticas de estas innovaciones jurídicas en el contexto de los Estados plurinacionales; las contradicciones entre el "espíritu del buen vivir" y las metas extractivistas de Bolivia y Ecuador ${ }^{16}$

Un abordaje comparativo de los corpus jurídicos que van más allá de los asuntos humanos también excede las posibilidades de este artículo; no obstante, quiero remarcar algunas cuestiones. Los derechos asignados a los animales o bien a la Pachamama no suponen un simple avance legal sino una interpelación de nuestro ethos occidental. Pese a sus diferencias -una ética extensionista de matriz antropocéntrica versus una ética biocéntrica-, ambos ambientalismos se erigen como nuevas moralidades con creciente consenso.

La ética animalista es comúnmente concebida como extensionista, en tanto se amplía una condición moral antes solo reservada a los humanos a un conjunto de no humanos. A diferencia de las posturas antropocéntricas tradicionales, buena parte de los animalistas considera que los derechos no deben contemplar únicamente a las personas humanas.

Una perspectiva biocéntrica, en cambio, parte de la existencia de valores intrínsecos en el ambiente, independiente de los intereses y utilidades de los humanos (Gudynas, 2015: 41). Recordemos que, amén de las cosmovisiones indígenas, el biocentrismo latinoamericano es influenciado por los autores de la ecología profunda. La ética holista de la deep ecology no se enfoca en individuos o especies dotados de propiedades particulares, sino en preservar un bien común sin perturbar la interdependencia de los componentes orgánicos y abióticos de un medio ambiente (Descola, 2012: 293).

Las críticas al antropocentrismo convencional ${ }^{17}$ por parte de ciertos colectivos occidentales -en el caso de los animalistas- o bien la renovada fe en un paradigma biocéntrico -en el caso de los impulsores del Buen Vivirnos trae ecos del célebre supuesto de Latour (2007): nunca fuimos modernos. La sociedad occidental jamás ha salido de la vieja matriz antropológica. Con la actual crisis ecológica, la "civilización" ya no puede pensarse como exterior a la naturaleza y a las demás culturas. Un colectivo que debe ocuparse del aire, el mar, de las

\footnotetext{
ecologista y la ecomarxista. Existe, en particular, una fuerte crítica al capitalismo y el desarrollo en muchas apropiaciones del término.

16 Véase Acosta (2010: 17-19); Schavelzon (2015); Gudynas (2009); Gudynas et al. (2011); Tortosa (2009); Escobar (2011); Rivera Cusicanqui (2010: 56-62); Alonso González y Macías Vázquez (2015). Respecto de la "domesticación" del Buen Vivir y las estrategias convencionales de desarrollo en el gobierno de Evo Morales en Bolivia, véase Gudynas (2013).

${ }^{17}$ Recordemos que en una postura antropocéntrica convencional o bien narcisista -en los términos de Viveiros de Castro-, los no humanos se definen de manera tautológica por su falta de humanidad: el hombre y sus atributos representan el parangón de dignidad moral de la que los demás existentes carecen (Descola, 2012: 378).
} 
bestias salvajes y domésticas, no solo no es moderno sino que está sumergido en la común humanidad y es tan antropológico como todas las otras culturas.

Luego de esta sucinta exposición de algunas innovaciones jurídicas que se interrogan más allá de la agencia humana, repasemos ahora los postulados de la corriente de pensamiento que ha servido de sustento a la militancia contemporánea a favor del derecho animal. Para fundamentar mi argumentación, retomaré brevemente mi etnografía sobre movimientos contra la tracción a sangre del Área Metropolitana de Buenos Aires, cuyos resultados han sido vertidos en un trabajo de más largo aliento (Carman 2017).

\section{El surgimiento del antiespecismo}

Los promotores de esta ética sin especies -o bien ética interespecie- resaltan que las diferencias físicas entre humanos y animales no deben ser el fundamento para una discriminación en el trato dispensado a los animales no humanos, dado que tenemos importantes semejanzas en cuanto a las capacidades de sentir dolor, placer y otro tipo de emociones.

Nuestra continuidad material con los animales - uno de los presupuestos básicos occidentales- es aludida por los antiespecistas desde el mismo nombre que los aúna, aunque de un modo paradojal. Parafraseando la famosa sentencia de Foucault (2012: 139) sobre la época clásica, pareciera que todo su ser quedase abarcado en el nombre elegido para designarlos.

Si Darwin postula una condición biológica común entre animales y humanos -la animalidad-, ellos infieren que hay una condición moral también común. Las diferencias físicas son, bajo este punto de vista, moralmente irrelevantes: "La igualdad de las especies es la conclusión lógica de la moralidad postdarwiniana" (Ryder, 2005, mi traducción).

Inspirado en la doctrina utilitarista de Bentham, Peter Singer ha sido uno de los principales portavoces de esta postura. Una de las máximas antiespecistas gira en torno a extender el principio básico de igualdad entre los humanos a los animales no humanos. Esta igualdad, sostiene Singer (2011: 17-21), no depende de la inteligencia, fuerza física u otros factores, sino que es una idea moral.

El énfasis de Singer está puesto no solo en la interioridad que se comparte con los animales sino también en las materialidades afines: los vertebrados mamíferos afirma el autor - tienen una compleja corteza cerebral; sus sistemas nerviosos son casi idénticos a los nuestros y sus reacciones ante el dolor, extraordinariamente parecidas (ibíd.: 29).

La postura de los antiespecistas es descripta como sensocéntrica: su foco de interés no está puesto en la totalidad de los vivientes u organismos abióticos, sino exclusivamente en aquellos animales -humanos y no humanos- que son identificados como sintientes. Los animales que no cuenten con un sistema nervioso central ni con una interioridad semejante a la nuestra quedarán, pues, fuera de esta comunidad moral.

Pese a no aparecer mencionado en su célebre Liberación animal, buena parte de la controvertida posición de Singer nos remite al filósofo griego Epicuro (341-270 a. C.). En ambos autores encuentro una limitación similar: el gesto de fundar una ética basada casi exclusivamente en la minimización del dolor de cada individuo, humano o animal según el caso ${ }^{18}$.

Las saudades antiespecistas presentan asimismo un aire de familia con aquellos mitos amerindios que evocan el continuum cultural de los seres antes de la especiación, cuando el hombre no se había separado del animal ${ }^{19}$. En ambos casos parece subsistir una nostalgia por ese mundo sin discontinuidades materiales pronunciadas; discontinuidades de las que -desde el punto de vista de los antiespecistas- luego se valdrán los humanos para cometer las peores atrocidades sobre el reino animal.

Estas concordancias no nos deben a llevar a perder de vista los profundos contrastes entre la teoría antiespecista y las ontologías amerindias animistas. En efecto, la filosofía antiespecista no escapa a un patrón ontológico naturalista. La idea de antiespecismo se asienta en el marco de una "naturaleza continua" (Foucault, 2012: 177) que es previa a la representación que se haga de ella y, como tal, característica de nuestro modo de ver el mundo. Aquello que los antiespecistas ponen en jaque no es el andamiaje clasificatorio del mundo animal propio de la sociedad moderna occidental, sino el tratamiento diferencial que les es dispensado a las especies en virtud de dicha clasificación. Se busca revertir, específicamente, aquel trato indigno que la modernidad occidental impuso a las especies no Homo Sapiens.

Autores como Singer (2011) y Spiegel (1996 en Passariello, 1999: 21) trazan un paralelo entre la esclavitud humana y la opresión de los animales no humanos por parte de los humanos: para ambos, el racismo y el especismo son prácticamente la misma cosa. Peter Singer (2011: 103) incluso compara los experimentos de los médicos nazis con prisioneros judíos, rusos y polacos con aquellos desarrollados por los científicos con cerdos, y cita al escritor Isaac Bashevis Singer para cerrar su razonamiento: "En su comportamiento con las criaturas [animales], todos los hombres [son] nazis".

\footnotetext{
18 Una referencia a los postulados filosóficos de Epicuro puede encontrarse en Carman, 2011: capítulo IV.

19 Respecto de los mitos amerindios, véase Descola (2012: 2024), Viveiros de Castro (2010) y especialmente, las descomunales Mitológicas de Lévi-Strauss (1968, 2002, 2009, 2010).
} 
El animal es enfocado básicamente como víctima de una manipulación y un sacrificio por parte de la sociedad humana, al cual debe restituírsele la calidad de sujeto que le ha sido expropiada. Para Regan -otro de los principales autores antiespecistas-, los animales no humanos son sujetos de una vida que tiene un valor inherente, no instrumental, y por lo tanto tienen el derecho de ser tratados de acuerdo a ese valor en sí (Lira, 2013: 75).

Bajo esta perspectiva, se diluye -0 al menos se deja en suspenso- la ambigüedad que ha caracterizado a la animalidad desde comienzos de la época moderna, unida a la representación de una bestialidad voraz, cargada -como retrata Foucault (2012: 292-293)- de poderes inquietantes y nocturnos.

\section{La jerarquización de los humanos}

Si "conocer bien alguna cosa es ser capaz de atribuirle el máximo de intencionalidad" (Viveiros de Castro, 2013: 24), esta "puesta en valor" de la intencionalidad animal sirve como argumento para objetar las prácticas abusivas sobre ellos. Este es el caso de los movimientos contra la tracción a sangre en el Área Metropolitana de Buenos Aires, que reivindican las cualidades de los caballos nobleza, buen corazón-al mismo tiempo en que batallan para que el carrero abandone el uso del caballo en su actividad laboral. Junto a veterinarios, abogados y otros especialistas, estas agrupaciones proteccionistas instruyen a rescatistas independientes respecto de cómo identificar a un caballo "maltratado por un carrero"20. A partir de diversos medios -charlas, folletos o por las redes socialesse divulgan los pasos para lograr incautar un caballo herido: realizar la denuncia; perseguir al carrero y pasar las coordenadas a la policía; convocar a un veterinario para que certifique el daño; sacar fotos para que la denuncia penal prospere; contactar a una ONG no solo para "dar contención al equino maltratado" sino para impulsar la causa y aportar pruebas.

Los carreros son vistos por estos grupos proteccionistas como un cuerpo obsceno en el espacio público: un "sobrepeso para el caballo" y un estorbo visual que "ofende a los ojos". Ellos encarnan la peor combinación imaginable: vivir de los desechos y usar un animal noble para un propósito ruin. La interioridad de estos actores no es jamás tematizada, como si esta fuese estructuralmente deficitaria o solo se expresara en prácticas de sacrificio y sumisión de otros seres vivientes. Citemos un fragmento de una entrevista para ilustrar esta cuestión:

"Actúan subrepticiamente, como cucarachas. [...] Ahora vos ves que se ha formado una subespecie: gente sin cultura, sin sensibilidad. [...] Yo me doy

\footnotetext{
${ }^{20}$ Las frases entre comillas corresponden a fragmentos de entrevistas, entradas de adherentes al blog Proyecto Caballos Libres o bien a extractos de charlas de concientización sobre el maltrato equino impartidas por diversos profesionales en el Gran Buenos Aires entre 2012 y 2016.
}

cuenta enseguida, es un don que tengo. [...] Pero el ser pobre no te da derecho a ser cruel. Ellos fueron castigados y van a ser crueles no sólo con el pobre angelito [refiriéndose al caballo], sino con la mujer, los hijos... No se detienen. [...] Buenos Aires está contaminada". (Entrevista a la fundadora de Proyecto Caballos Libres, 2012).

Estos movimientos contra la tracción a sangre retoman como propios los postulados antiespecistas consignados en el apartado anterior. Nótese la paradoja entre la proclamación de una ética común a las especies y la alusión a los pobres como una subespecie, como si hubiera un carácter antojadizo en su condición de humanidad: a veces se es humano, a veces se es bestia. El estatus ontológico de esa población se vería así, al decir de Butler (2010: 51), comprometido y suspendido.

Recordemos que los antiespecistas enfatizan la posesión de sensibilidad como una "condición 'umbral' para la admisión en la comunidad de seres detentadores de derechos basados en la justicia" (Nussbaum 2007: 356). Si los cartoneros no tienen sentimientos, ¿pues entonces tampoco han de merecer justicia? Lejos de problematizar injustas condiciones de distribución de la riqueza, estos alegatos concluyen que los carreros merecerían una pena semejante al daño que han causado a los animales: "Que estos tipos tiren ellos de sus carros y dejen a los caballos en paz".

Estos movimientos proteccionistas adscriben al más prosaico naturalismo occidental cuando -basándose en consignas antiespecistas- establecen una jerarquía entre humanos de mayor o menor gradación moral y expulsan a los carreros de esa anhelada ética interespecie.

En articulación con lo anterior, veamos a continuación de qué modo diversos colectivos de Occidente como los antiespecistas, los biotecnólogos y los conservacionistas establecen diversas jerarquías entre animales.

\section{La jerarquización de los animales}

El antiespecismo retoma valores de las sociedades protectoras de animales del mundo anglosajón, así como de la Declaración de los Derechos del Animal21. La interpelación moral de los antiespecistas, sin embargo, no solo echa raíces en el pasado: en otros campos de Occidente también opera un significativo cuestionamiento de los límites entre lo animal y lo humano. Tal es el caso de prácticas biotecnológicas como los xenotransplantes -transplantes de órganos y tejidos de animales a seres humanos con enfermedades terminales- y la transgénesis, que supone transferencia de genes de humanos a animales y viceversa. En

\footnotetext{
${ }^{21}$ La Declaración Internacional de los Derechos del Animal, promulgada en 1978 por parte de la Liga Internacional de Derechos del Animal, fue posteriormente rubricada por la ONU y la UNESCO (Mastrangelo, 2015).
} 
tales campos opera no solo una reclasificación de los criterios que distinguen lo animal y lo humano, sino una revalorización de las relaciones entre ambos:

"(...) la naturaleza, humana o animal, es construida, y cuestionada, mediante taxonomías modeladas sobre la base de intereses históricos y culturales específicos, que son proyectados como progresistas y, por lo tanto, moralmente justificados". (Papagaroufali, 2001: 278-279).

Lo que quiero remarcar aquí es que colectivos de Occidente que cuestionan, cada uno a su modo, las fronteras convencionales animal-humano, muestran coincidencias en su autorrepresentación. Ya sean los antiespecistas o los biotecnólogos, estos colectivos se exhiben a sí mismos no solo como opositores a un antropocentrismo medieval ${ }^{22}$ sino como portadores de un pensamiento o práctica de vanguardia.

Asimismo, en todos ellos existe una distancia entre los postulados de una animalidad abstracta y aquella que se negocia en el marco de relaciones específicas de carne y hueso.

Ahora bien, es importante aclarar que la defensa del valor de todas las vidas animales por parte de los proteccionistas -que retoman explícitamente las premisas antiespecistas- no es compartida por otras corrientes ecologistas. Los conservacionistas, por ejemplo, centran su preocupación en la protección de la biodiversidad y usualmente están obligados a apreciar las especies animales raras o amenazadas por encima de otras (Milton, 2002: 124). Se trata de dos paradigmas diferenciados: frente a la igualación de los antiespecistas -centrada en la autonomía individual y la personalidad de los animales- se alza la perspectiva conservacionista, que establece una jerarquía de animales con diversas prioridades de protección en función de ciertos parámetros de biodiversidad definidos científicamente (ibíd.: 122-128).

Pese a que los antiespecistas postulan filosóficamente la igualdad de todos los animales, ellos también ponen en juego criterios de jerarquización de los animales, así como de los humanos; tal como ejemplificamos en los últimos párrafos del apartado anterior respecto de algunos movimientos contra la tracción a sangre. Recordemos además aquellos polémicos pasajes de Liberación animal -una suerte de biblia de los animalistas- en los cuales Singer arguye:

"Es legítimo aducir que algunos rasgos de ciertos seres hacen que sus vidas sean más valiosas que las de otros; pero sin duda habrá algunos animales no humanos cuyas vidas, sea cual fuere el estándar utilizado, sean más valiosas que las de

\footnotetext{
${ }^{22}$ La expresión pertenece a Tapper (1994: 59).
}

algunos humanos. Un chimpancé, un perro o un cerdo, por ejemplo, tendrán un mayor grado de autoconciencia y más capacidad para establecer relaciones significativas con otros que un recién nacido con gran retraso mental o un anciano en estado avanzado de demencia senil. Por tanto, si basamos el derecho a la vida en estas características tendremos que garantizárselo a estos animales en la misma medida, o incluso mayor, que a ciertos humanos retrasados o con debilidad senil". (Singer, 2011 [1975]: 36).

Los debates en tal sentido son múltiples. Junto a otros filósofos y médicos, Singer ha defendido el uso de personas en estado de muerte cerebral como fuente de órganos. Esta postura se contrapone a la de otros científicos europeos y estadounidenses que afirman que los grandes monos y otros animales "superiores" deben ser sacrificados en beneficio de los humanos, cuyo valor moral es considerado superior a los primeros (Papagaroufali, 2001: 279).

Lo significativo es que los mismos criterios que la modernidad ha utilizado históricamente para negar el valor de la vida a los seres no humanos -inteligencia, sensibilidad, lenguaje- son ahora utilizados para requerir ese valor basado en tales condiciones; lo cual muestra, como bien analiza Lira (2013: 84), "la fragilidad inherente al uso de indicadores constituidos dentro del universo humano" (mi traducción). Autores como Naconecy (en Lira, 2013: 89) incluso denuncian el especismo dentro de la filosofía animalista: si contemplamos la posición de autores como Singer o Regan, que toman el criterio de sensibilidad para delinear el estatuto moral de los animales, dejaríamos fuera de esa esfera a los animales no sintientes como los insectos, a pesar de ser el mayor y más diversificado grupo de animales existentes en la Tierra. El modelo animalista resulta, según Naconecy, contradictorio: sería más adecuado hablar de una ética de los vertebrados -que representan solo un $2 \%$ de las especies- en lugar de referirnos a una ética animal23.

En contraste con esta postura, recordemos que los innovadores derechos de la naturaleza consagrados en la Constitución de Ecuador apuntan a resguardar los derechos de todos los animales, plantas y ecosistemas:

"Se debe asegurar la conservación incluso de especies que nos resulten feas y desagradables, o de otras que pueden ser completamente inútiles para los fines humanos. Todas ellas tienen el derecho a proseguir sus procesos ecológicos y evolutivos". (Gudynas, 2015: 54).

Para comprender cabalmente esta cuestión, creo que es importante volver a repasar algunas diferencias entre

\footnotetext{
${ }^{23}$ Lira (2013: 89-91). La posición de Regan es aún más excluyente, pues centra su defensa únicamente en los mamíferos (ibíd.).
} 
las visiones biocéntricas y las antropocéntricas. Como sabemos, buena parte de las comunidades indígenas estudiadas por los antropólogos se corresponden con el biocentrismo: las personas se ven a sí mismas y al resto de su entorno como parte de un sistema holístico continuo.

Los movimientos proteccionistas que comparten tout court las creencias antiespecistas nos remiten a un sensocentrismo cuyas características ya fueron detalladas, y que se corresponde básicamente con un antropocentrismo crítico: existe una percepción de los humanos como seres separados de la naturaleza, aunque ese vínculo incluya intercambio, cuidado y respeto (Pretty et al., 2008: 3).

Quienes adhieren a un biocentrismo basan sus visiones de lo natural en creencias espirituales, mientras que los cultores de un antropocentrismo sui generis depositan mayormente su confianza en la ciencia y las enseñanzas de la educación formal (ibíd.: 4).

Pese a que existen varias divergencias prácticas con los paradigmas biocéntricos, la más evidente $-y$ con frecuencia la única mencionada por sus detractores-es el antropocentrismo dominante: una implacable conquista del medio ambiente por parte de los seres humanos. Zaffaroni (2012: 89-96) asocia este antropocentrismo radical con aquellos sectores, por lo general grandes corporaciones, que viven la ecología como una amenaza de quitar al hombre su rol de dominio de la naturaleza.

Una postura antropocéntrica subalterna estaría representada por un set de prácticas centrado en la supervivencia de un grupo, como aquel que describe Einarsson (1993: 76) respecto de los pescadores de Islandia: "Una visión básicamente utilitaria (...), sin demasiado espacio para experiencias románticas de comunión con la naturaleza".

Por último, creo que existe un antropocentrismo inevitable en nuestra concepción de los vínculos con los no humanos. El lugar que ocupen los animales en las sociedades, así como nuestra consideración sobre los lazos que ellos tejen entre sí y con los humanos, siempre ha de depender de los modos en que los humanos nos pensemos a nosotros mismos en relación con un determinado entorno ${ }^{24}$.

\section{El giro animal del pensamiento}

Apoyado en muy diversas fuentes -la etología; la sociobiología; la neurología; los escritos de Derrida, Singer o Rawls; la evidencia de los avances tecnológicos o la literatura del embodiment-, un ecléctico conjunto de filósofos, ecologistas profundos, juristas e intelectuales

\footnotetext{
24 Véase Douglas (1998: 147); Juan (2001: 173-179); y Lira (2013: 93). Respecto de las diferencias entre una asignación de valores antropogénica y una antropocéntrica, véase Gudynas (2015: 52).
}

reivindica políticas de la animalidad $^{25}$ que signifiquen "una apertura ética de la dignidad" (Penchaszadeh, 2011: 132) hacia estos "agentes" que son un fin en sí mismo y que "buscan una existencia floreciente" (Nussbaum, 2007: 333).

En un dossier reciente de una revista argentina, un grupo de intelectuales propone no solo escuchar y "recoger el dolor de esas voces", sino también "leyes concretas que amparen la fragilidad de la vida" (Cragnolini, 2011: 115). Se trata de extender, en sus palabras, el problema de la hospitalidad y la justicia hacia ese "radicalmente otro que sufre" (Penchaszadeh, 2011: 131).

Ante la vehemencia de sus argumentos, por un instante el lector cree estar ante un movimiento que persigue la liberación de los desclasados, o el fin del racismo y el hambre mundiales. Los padecimientos de ese otro ¿refieren quizás a las muertes por desnutrición en la provincia argentina de Misiones, la intemperie de los sin techo, las condiciones de los presos de Guantánamo o los torturados en Afganistán? Nada de eso. La radicalidad del planteo no aspira a garantizar derechos a los humanos considerados superfluos o tratados como residuos, sino a la proclamación de nuevos derechos a los animales. En sus términos, se procura "deconstruir la circunscripción del problema ético/político al orden humano" (Penchaszadeh, 2011: 131) incorporando para tal fin a los animales.

Luego de proclamar una suerte de relativismo cultural naïf de las especies ${ }^{26}$, la filósofa norteamericana Nussbaum -reciente ganadora del Premio Príncipe de Asturias- no duda en afirmar la equivalencia moral entre animales humanos y animales sensibles:

"(...) cada especie tiene un modo de vida distinto y unos fines diferentes; a su vez, dentro de una especie dada, a cada vida se le reconocen múltiples y heterogéneos fines. (...) si una criatura tiene o bien la capacidad de sentir placer y dolor, o bien la capacidad de moverse de un lugar a otro, o bien la capacidad de emoción y afiliación (...) entonces posee una posición moral". (Nussbaum, 2007: 347 y 357).

Si la postura clásica del humanismo kantiano no asume

\footnotetext{
${ }^{25}$ Retomando un concepto de Isabelle Stengers y en un sentido más ambicioso, Latour $(2004,2011)$ propone una nueva cosmopolítica que asuma el desafío de la hibridación de los colectivos humanos y no humanos.

26 Con ironía, Mastrangelo (2015) se pregunta si estos nuevos derechos que se confieren a los animales han de alcanzar también a aquellos parásitos que enferman al hombre. Una objeción similar suele plantearse a algunas corrientes de ecología profunda: "...uno ve esbozarse, bajo pretexto de luchar contra (...) el antropocentrismo, un rechazo del humanismo (...). ¿Verdaderamente hay que considerar que el bacilo de Koch o el mosquito Anopheles tienen el mismo derecho a la vida que un niño enfermo de tuberculosis o malaria?" (Löwy, 2011: 29).
} 
un deber hacia los animales ${ }^{27}$, los animalistas destacan en cambio que la capacidad de razón y de reciprocidad moral no deben ser las únicas fuentes de dignidad de los seres vivientes. El fin de la justicia, agrega esta filósofa, ha de ser garantizar una vida digna a muchas clases de seres. Que los animales sensibles no encuentren obstáculos -por decirlo en un lenguaje spinoziano- a perseverar en su ser.

No hay en estas formulaciones, a mi criterio, ni gran novedad ni ruptura sustantiva con el statu quo; veamos por qué.

El pensamiento occidental reactualiza bajo su propio horizonte de sentido lo que muchas sociedades indígenas no han dejado de experimentar en su vida ordinaria desde muchísimo tiempo atrás: la atribución de humanidad a los animales, la facultad de razonamiento analógico $^{28}$ y la vivencia de una interconexión entre los seres. Señalemos un solo ejemplo: los animalistas desafían la disociación moral entre humanos y animales que funda el naturalismo occidental, y postulan una dignidad común que trasciende la frontera entre especies. Aunque en un sentido restringido -pues su demarcación moral abarca solo a los animales sintientes y no así a las plantas o al resto de la naturaleza-, los animalistas reivindican una humanidad compartida, entendida aquí no como especie (humankind) sino como idea moral (humanity). Esta relevante distinción es tributaria de diversas etnografías amazónicas: para los amerindios, la condición de humanidad (humanity) es un referencial común, una forma originaria de todos los seres de la naturaleza ${ }^{29}$. La calidad de sujeto atribuida por estas sociedades indígenas a los animales no es igual, claro está, a la extensión moral que funda la política de compasión de los animalistas, enfocada en evitar un sufrimiento únicamente a ciertas especies.

¿Y por qué no habría ruptura con el statu quo? El giro animal del pensamiento no propone un horizonte político claro: si bien sus defensores alegan que no se trata de la aceptación de una perspectiva biológica de la cultura o de una renovada piedad hacia las bestias $^{30}$, ambos pareceres no cesan de comparecer en sus escritos. Tampoco se tematiza qué ha de suceder cuando algún derecho animal entre en conflicto con las posibilidades de supervivencia de un grupo humano específico, como en el caso de las disputas en torno a la tracción a sangre que hemos descripto brevemente. El interés por conferir nuevos derechos a distintas

\footnotetext{
27 Un repaso por las posturas con mayor o menor predicamento respecto de los animales en la tradición judeocristiana y la filosofía moderna occidental puede consultarse en Nussbaum (2007: 321-361). ${ }^{28}$ Véase al respecto Willis (1994), Lévi-Strauss (1975: 25-33 y 60) y Ellen (1996: 114).

${ }^{29}$ Véase Descola (1998) y Viveiros de Castro (2002). Por citar solo un ejemplo, los makunas de la Amazonia conciben a los animales cazables y a los peces como dotados de conocimiento, capacidad de acción intencional y otros atributos humanos (Århem, 2001).

${ }^{30}$ Véase Galiazo (2011).
}

clases de animales (ya sean de compañía, de corral o mamíferos superiores) suele ser autonomizado de las luchas por lograr una mejor distribución de la riqueza; precisamente en una coyuntura mundial en la cual la brecha entre ricos y pobres no ha hecho sino aumentar a niveles que décadas atrás resultaban inimaginables.

Una última objeción remite a la clásica discordancia entre la Filosofía y la Antropología: el punto de partida desde el cual observamos e interpretamos el mundo.

\begin{abstract}
“El etnólogo no se siente obligado, como el filósofo, a tomar por principio de reflexión las condiciones de ejercicio de su propio pensamiento o de una ciencia que es la de la sociedad de su tiempo, a fin de extender tales verificaciones a un entendimiento cuya universalidad no podrá ser sino hipotética y virtual. Preocupado por los mismos problemas, hace un recorrido inverso (...). En vez de la hipótesis de un entendimiento universal prefiere la observación empírica de entendimientos colectivos cuyas propiedades, en cierta manera solidificadas, se le vuelven manifiestas merced a innumerables sistemas concretos de representaciones". (Lévi-Strauss, 1968: 20).
\end{abstract}

En tal sentido, y tal como advierte Tapper (1994: 49), los filósofos tienden a moralizar sobre los animal rights sin atender los contextos socio-culturales específicos en los que tales perspectivas se vuelven inteligibles ${ }^{31}$. El desvelo especulativo por "el mundo que deberíamos tener" desanclado de los problemas reales de poblaciones específicas es una de mis principales objeciones, pues, a las formulaciones filosóficas del giro animal.

\section{Conclusiones}

Como hemos visto a lo largo del artículo, los antiespecistas se apartan de los postulados más abiertamente colonialistas del antropocentrismo y buscan atenuar parte de sus asimetrías ${ }^{32}$. A diferencia del antropocentrismo dominante, los proteccionistas no creen que los animales tengan solo valores instrumentales (Felipe, 2009: 7).

Si bien se proclama que todos los animales son iguales $-\mathrm{y}$ deben ser tratados como tales-, no todas las especies tienen igual valor para los antiespecistas. Esta jerarquización no es privativa de nuestro ethos occidental: las sociedades indígenas también distinguen a las especies animales en diversos rangos de proximidad o distancia en virtud de su experiencia práctica con

\footnotetext{
${ }^{31}$ La Antropología puede ser concebida, según la célebre formulación de Ingold, como una filosofía con la gente adentro (Viveiros de Castro, 2010).

32 Sobre las vinculaciones asimétricas que promueve el antropocentrismo, véase Gudynas (2015: 156).
} 
estas $^{33}$. La particularidad de los occidentales consiste en que su jerarquización de las especies no es sino el resultado de una proyección de las capacidades mentales humanas como únicas en el universo:

\section{"(...) los organismos vivientes que no poseen razón son clasificados como 'inferiores' (cualquiera que sea la 'especie' a la que pertenecen), mientras que los que la tienen, aunque sea parcialmente (por ejemplo los monos), son clasificados como 'superiores'. Con base en esa evaluación, los babuinos y los chimpancés son presentados como la fuente principal de información sobre el estado 'originario' de la naturaleza humana, reconocido como presocial, irracional y 'salvaje'". (Papagaroufali, 2001: 281).}

Por otra parte, hemos visto que los grupos metropolitanos en contra de la tracción a sangre -que retoman explícitamente el corpus antiespecista- elaboran una marcada jerarquización de humanos y apelan al etnocentrismo a la hora de juzgar el comportamiento de los carreros, cuyo presunto déficit moral derivaría de una posición inferior en la escala social.

$$
* * *
$$

La somera caracterización que hemos trazado a lo largo del artículo entre posturas biocéntricas, sensocéntricas y antropocéntricas no excluye los interminables ecos, matices dialógicos y reflejos recíprocos (Bajtín, 1982) de los enunciados ambientales que se echan a rodar en una cadena interminable y de los cuales se apropian los distintos movimientos y actores.

Veamos un ejemplo: en el marco del biocentrismo, todas las especies vivientes tienen igual importancia y merecen ser protegidas ${ }^{34}$. En el proteccionismo no hay tal deber moral de cuidado del conjunto, sino únicamente de los individuos - por lo general frágiles o dañados- de una especie valorada, como hemos visto en el caso de los defensores de los caballos.

Un colectivo proteccionista puede tener, sin embargo, influencias biocéntricas. El influyente video Terrícolas cuya circulación ha sido determinante en la conversión de veganos y animalistas- engloba bajo esa denominación a todos los habitantes de la Tierra. Su postura tiene puntos de contacto con la ética biocéntrica, en el sentido de que los humanos deben proteger a los miembros de esa comunidad biótica de la Tierra para que puedan

\footnotetext{
${ }^{33}$ Véase el caso de los huaoranis en Rival (2001: 189), de los achuares en Descola (2012: 29-31) y de los qom en Medrano, Maidana y Gómez (2011). Un interesante análisis sobre el distinto estatus simbólico que es conferido a los animales según como estos sean valorados o temidos por quienes los clasifican puede consultarse en Hell (2001: 237). Véase además Milton (2000: 239-240 y 2002: 79-83); Descola (2012: 139-140); y Lira (2013: 85-91).

${ }^{34}$ Véase Gudynas (2015: 67-8)
}

seguir sus propios procesos de vida ${ }^{35}$.

A la inversa, ciertos movimientos biocéntricos contemporáneos pueden valerse de algunos postulados de los filósofos zooéticos utilitaristas como singer en su defensa de los derechos de todo lo viviente.

Por otra parte, que un número creciente de ecologistas se sienta "parte de la naturaleza" no invalida que esta continúe siendo considerada una entidad sagrada custodiada por humanos detentores de un saber; y cuyos tesoros, "pedidos" y agonías necesitan continuas traducciones. No todas las traducciones tendrán, claro está, la misma posibilidad de consagrarse como legítimas: solo la palabra autorizada de cierta elite científica ha de trazar la línea que separa lo ambientalmente correcto de aquello que no lo es. Si en las épocas premodernas la naturaleza era temida y "dominaba" a los seres humanos, la visión paternalista occidental concibe a la naturaleza como una entidad frágil que ha de ser protegida ${ }^{36}$.

No alcanza con definir, pues, las diferencias entre visiones biocéntricas y antropocéntricas, ni idealizar el paso de una visión antropo a una bio. Resulta insoslayable observar, en cada caso, qué colectivo humano es portador de esa visión; cuál es su posición en la estructura social; cómo esa visión se corresponde con determinadas políticas; y de qué modo esta es impuesta o no a otros grupos.

Buenos Aires, 29 de septiembre de 2017

\section{Bibliografía}

Acosta, Alberto. (2010). El buen vivir, una utopía por (re) construir. En CIP-Ecosocial - Boletín ECOS (11).

Agamben, G. (2002) [1998]. Homo sacer I. Madrid: Editora Nacional.

Alonso González, P. y Macías Vázquez, A. (2015). An ontological turn in the debate on Buen Vivir - Sumak Kawsay in Ecuador. En Latin American and Caribbean Ethnic Studies, 10(3), 315-334.

Århem, K. (2001). La red cósmica de la alimentación. La interconexión de humanos y naturaleza en el noroeste de la Amazonia. En P. Descola y G. Pálsson (eds.), Naturaleza y sociedad. Perspectivas antropológicas (pp. 214-236). México D. F.: Siglo XXI.

Bajtín, M. (1982). Estética de la creación verbal. México D.F.: Siglo XXI.

\footnotetext{
${ }^{35}$ Véase Gudynas (2015: 68-9) y Lira (2013). La ética biocéntrica de Paul W. Taylor también es retomada en algunas argumentaciones animalistas (véase Felipe, 2009: 16-26).

${ }^{36}$ Véase Latour (2004: 80-81).
} 
Beck, U. (2009). La sociedad del riesgo global. Madrid: Siglo XXI.

Bhabha, H. K. (2013). Nuevas minorías, nuevos derechos. Buenos Aires: Siglo XXI.

Boltanski, L. y Chiapello, È. (2002). El nuevo espíritu del capitalismo. Madrid: Akal.

Bourdieu, P. (1991). El sentido práctico. Madrid: Taurus.

Butler, J. (2010). Marcos de guerra. Las vidas Iloradas. Buenos Aires: Paidós.

Carman, M. (2011). Las trampas de la naturaleza. Medio ambiente y segregación en Buenos Aires. Buenos Aires: Fondo de Cultura Económica-CLACSO.

Carman, M. (2017). Las fronteras de lo humano. Cuando la vida humana pierde valor y la vida animal se dignifica. Buenos Aires: Siglo XXI.

Chaplier, M. (2005). L'anthropologie de la nature: de la théorie à l'attitude prospective. En LAAPapers (1).

Cragnolini, M. B. (2011). Políticas de la animalidad. En Pensamiento de los confines, 27, 109-116.

Descola, P. (1996). In the Society of Nature: A Native Ecology in Amazonia. Nueva York: Cambridge University Press.

Descola, P. (2005). Más allá de la naturaleza y la cultura. En Etnografías contemporáneas (1), 93-114.

Descola, P. (2009). Human natures. En Social Anthropology (2), 145-157.

Descola, P. (2012). Más allá de la naturaleza y la cultura. Buenos Aires: Amorrortu.

Descola, P. (1998). Estrutura ou sentimento: a relação com o animal na Amazônia. En Mana, 1(4), 23-45.

Douglas, M. (1998). Estilos de pensar. Ensayos críticos sobre el buen gusto. Barcelona: Gedisa.

Einarsson, N. (1993). All animals are equal but some are cetaceans. Conservation and culture conflict. En K. Milton (ed.), Environmentalism. The View from Anthropology (pp. 73-84). London: Routdledge.

Ellen, R. F. (1996). The cognitive geometry of nature: a contextual approach. En P. Descola y G. Pálsson (eds.), Nature and Society. Anthropological Perspectives (pp. 124-145). Londres: Routledge.

Escobar, A. (2000). El lugar de la naturaleza y la naturaleza del lugar: ¿globalización o postdesarrollo? En
E. Lander (ed.), La colonialidad del saber: eurocentrismo y ciencias sociales. Perspectivas latinoamericanas (pp. 68-87). Buenos Aires: CLACSO-UNESCO.

Escobar, A. (2011). Una minga para el posdesarrollo. En Signo y Pensamiento (58), 306-312.

Felipe, S. T. (2009). Antropocentrismo, sencientismo e biocentrismo. En Revista Páginas de Filosofia, 1(1), 2-30.

Foucault, M. (2012) [1966]. Las palabras y las cosas. Una arqueología de las ciencias humanas. Buenos Aires: Siglo XXI.

Frazer, J. G. (2011) [1890]. La rama dorada. Magia y religión. México D. F.: Fondo de Cultura Económica.

Galiazo, E. (2011). El giro animal. En Pensamiento de los confines, 27, 97-108.

Giddens, A. (1995). La constitución de la sociedad. Buenos Aires: Amorrortu.

Gudynas, E. (2009). La ecología política del giro biocéntrico en la nueva Constitución de Ecuador. En Revista de Estudios Sociales (32), 34-47.

Gudynas, E. (2013). El malestar moderno con el buen vivir: reacciones y resistencias frente a una alternativa al desarrollo. En Ecuador Debate. Identidades y diferencias (88), 183-205.

Gudynas, E. (2015). Derechos de la naturaleza. Ética biocéntrica y políticas ambientales. Buenos Aires: Tinta limón.

Gudynas, E. y Acosta, A. (2011). El buen vivir o la disolución de la idea del progreso. En M. Rojas (ed.), La medición del progreso y el bienestar. Propuestas desde América Latina (pp. 103-110). México D. F.: Foro Consultivo Científico y Tecnológico de México.

Hell, B. (2001). Cazadores rabiosos. El dominio del salvajismo en el noroeste de Europa. En P. Descola y G. Pálsson (eds.), Naturaleza y sociedad. Perspectivas antropológicas (pp. 237-253). México D. F.: Siglo XXI.

Ingold, T. (1994a). Preface to the paperback edition. En T. Ingold (ed.), What is an animal? (pp. XXIII-XXIV). London: Routledge.

Ingold, T. (1994b). Introduction. En T. Ingold (ed.), What is an animal? (pp. 1-16). London: Routledge.

Ingold, T. (1994c). The animal in the study of humanity. En T. Ingold (ed.), What is an animal? (pp. 84-99). London: Routledge. 
Ingold, T. (2000). The perception of the environment. Essays on livelihood, dwelling and skill. London: Routledge.

Juan, S. (2001). La société inhumaine. Mal-vivre dans le bien-être. Paris: L'Harmattan.

Latour, B. (2004). Politiques de la nature. Comment faire entrer les sciences en démocratie. Paris: La Découverte.

Latour, B. (2007). Nunca fuimos modernos. Ensayo de antropología simétrica. Buenos Aires: Siglo XXI.

Latour, B. (2011). Politics of nature: East and West perspectives. En Ethics \& Global Politics, 4 (1), 71-80.

Le Quang, M. y Vercoutère, T. (2013). Ecosocialismo y Buen Vivir. Diálogo entre dos alternativas al capitalismo. Quito: IAEN.

Lévi-Strauss, C. (1968). [1964]. Mitológicas I. Lo crudo y lo cocido. México D. F.: Fondo de Cultura Económica.

Lévi-Strauss, C. (1975) [1962]. El pensamiento salvaje. México D. F.: Fondo de Cultura Económica.

Lévi-Strauss, C. (2002) [1968]. Mitológicas III. El origen de las maneras de mesa. México D. F.: Siglo XXI.

Lévi-Strauss, C. (2009) [1971]. Mitológicas IV. El hombre desnudo. México D. F.: Siglo XXI.

Lévi-Strauss, C. (2010) [1967]. Mitológicas II. De la miel a las cenizas. México D. F.: Fondo de Cultura Económica.

Lira, L. C. (2013). 'O outro lado do muro': natureza e cultura na ética animalista e no ativismo vegan. En Revista Anthropológicas, 24 (1), 67-102.

Löwy, M. (2011). Ecosocialismo: la alternativa radical a la catástrofe ecológica capitalista. Buenos Aires: Herramienta-El Colectivo.

Mastrangelo, A. (2015). Derechos de humanos y no humanos: una reflexión basada en dos estudios de caso etnográficos. En Caderno Eletrônico de Ciências Sociais, 3(1), 35-53.

Medrano, C., Maidana, M. y Gómez, C. (2011). Zoología qom: conocimientos tobas sobre el mundo animal. Santa Fe: Ediciones Biológica.

Merleau-Ponty, M. (1997). Fenomenología de la percepción. Barcelona: Península.

Milton, K. (1997). Ecologies: anthropology, culture and the environment. En International Social Science Journal, 49(154), 477-495.
Milton, K. (2000). Ducks out of water. Nature conservation as boundary maintenance. En J. Knight (ed.), Natural Enemies. People-wildlife conflicts in anthropological perspective (pp. 229-246). London: Routledge.

Milton, K. (2002). Loving Nature. Towards an ecology of emotion. London: Routledge.

Murrieta, R. S. (2001). A mística do Pirarucu: pesca, ethos e paisagem en comunidades rurais do Baixo Amazonas. En Horizontes Antropológicos, 7(16), 113-130.

Nussbaum, M. C. (2007). Las fronteras de la justicia. Barcelona: Paidós.

Papagaroufali, E. (2001). Xenotransplantes y transgénesis. Historias in-morales sobre relaciones entre humanos y animales en Occidente. En P. Descola y G. Pálsson (eds.), Naturaleza y sociedad. Perspectivas antropológicas (pp. 277-294). México D. F.: Siglo XXI.

Passariello, P. (1999). Me and my totem: cross-cultural attitudes towards animals. En F. Dolins (ed.), Attitudes to Animals. Views in Animal Welfare (pp. 12-25). Cambridge: Cambridge University Press.

Penchaszadeh, A. P. (2011). Resistencia de lo diverso: el animal y los límites de la política. En Pensamiento de los confines, 27, 131-135.

Pretty, J., Adams, B., Berkes, F., Ferreira de Athayde, S., Dudley, N., Hunn, E., Maffi, L., Milton, K., Rapport, D., Robbins, P., Samson, C., Sterling, E., Stolton, S., Takeuchi, K., Tsing, A., Vintinner, E. y Pilgrim, S. (2008). How Do Biodiversity and Culture Intersect? En Sustaining Cultural and Biological Diversity In a Rapidly Changing World: Lessons for Global Policy. Conferencia llevada a cabo en el American Museum of Natural History, Nueva York, NY.

Quignard, P. (2010). La barca silenciosa. Buenos Aires: El cuenco de plata.

Rival, L. (2001). Cerbatanas y lanzas. La significación social de las elecciones tecnológicas de los Huaorani. En P. Descola y G. Pálsson (eds.), Naturaleza y sociedad. Perspectivas antropológicas (pp. 169-191). México D. F.: Siglo XXI.

Rivera Cusicanqui, S. (2010). Ch'ixinakax Utxiwa: una reflexión sobre prácticas y discurso descolonizadores. Buenos Aires: Tinta Limón.

Rosset, C. (1965). Lettre sur les chimpanzés. Paris: Gallimard.

Ryder, R. (2005, Agosto 6). All beings that feel pain deserve human rights. En The Guardian. Recuperado 
de https://www.theguardian.com/uk/2005/aug/06/ animalwelfare.

Santos, B. de Sousa (1998). De la mano de Alicia. Lo social y lo político en la posmodernidad. Bogotá: Siglo del Hombre/Uniandes.

Schavelzon, S. (2015). Plurinacionalidad y Vivir Bien/ Buen Vivir. Dos conceptos leídos desde Bolivia y Ecuador post-constituyentes. Quito: Abya Yala/CLACSO.

Simondon, G. (2004). Deux leçons sur l'animal et I'homme. Paris: Ellipses.

Singer, P. (2011). Liberación animal. España: Taurus.

Tapper, R. L. (1994). Animality, humanity, morality, society. En T. Ingold (ed.), What is an animal? (pp. 4762). London: Routledge.

Tortosa, J. M. (2009). Sumak Kawsay, Suma Qamaña, Buen Vivir. En Aportes Andinos (28).

Turner, T. (2010). La producción social de la diferencia humana como fundamento antropológico de los derechos humanos negativos. En Revista de Antropología Social, 19, 53-66.

Viveiros de Castro, E. (2002). A inconstância da alma selvagem e outros ensaios de antropologia. Paris: Cosac \& Naufy.

Viveiros de Castro, E. (2010). Metafísicas caníbales. Líneas de antropología postestructural. Buenos Aires: Katz.

Viveiros de Castro, E. (2013). La mirada del jaguar. Introducción al perspectivismo amerindio. Buenos Aires: Tinta Limón.

Willis, R. (1994). Introduction. En R. Willis (ed.), Signifying Animals: Human Meaning in the Natural World (pp. 1-22). London: Routledge.

Zaffaroni, E. R. (2012). La Pachamama y el humano. Buenos Aires: Colihue. 